\title{
Acute myocardial infarction caused by blast injury of the chest
}

\author{
ANDRE KEREN, JOCHANAN STESSMAN, DAN TZIVONI \\ From the Bikur Cholim, Hadassah-Mount Scopus, and Hadassah-Ein Kerem Hospitals and Hebrew \\ University-Hadassah Medical School, ferusalem, Israel
}

SUMMARY A 51-year-old healthy man was hit in the chest by the shock-waves generated by an explosion, without being injured by any physical object. He felt immediate chest pain, but, in spite of electrocardiographic tracings highly suspicious for an acute anteroseptal infarction in the emergency room, he was discharged from hospital. The electrocardiogram recorded three weeks later was pathognomonic of anteroseptal infarction. Coronary arteriography performed four months later showed a complete obstruction of the left anterior descending coronary artery, with retrograde filling from the right coronary artery. It is assumed that the myocardial infarction was caused by the blast injury which induced an intimal tear and/or a subintimal haemorrhage in the left anterior descending artery with subsequent thrombosis. The lack of atherosclerosis in any other coronary arteries in this patient is noteworthy.

Blast injury is a special form of blunt trauma, inflicted by transmitted shock-waves generated by an explosion. In this type of injury the damage is induced by the impact of the positive pressure waves of air or water, without contact with an object. We report here a patient who after exposure to such a primary blast injury of air shock-waves suffered an acute myocardial infarction. Coronary cineangiography four months later disclosed complete obstruction of the left anterior descending coronary artery, without signs of atherosclerotic disease in any other coronary artery.

\section{Case report}

A 51-year-old man stood at the market place of Jerusalem at about 10 am on 29 June 1978. An explosive material placed by terrorists detonated, two people were instantly killed, and several others were injured. Our patient, who stood about 2 metres away from the explosion, felt a tremendous impact to his chest associated with immediate shortness of breath; he was thrown back by the air shock-waves generated by the detonation but was not injured by any physical object. Because of the chest pain he was taken to hospital immediately. In the emergency room the patient said that he had never had any previous cardiac complaints, including chest pain or shortness of breath, but mild diabetes was diagnosed five years earlier, and an electrocardiogram performed one year earlier was normal (Fig. 1). (This tracing was made available only a few months after all this happened.)

The first electrocardiogram in the emergency room was done $1 \frac{1}{2}$ hours after the explosion (Fig. 2 upper row) and it showed $Q$ in V3-4 with a tiny $R$ wave in $V 2$. Because of the persistence of the praecordial pain, the electrocardiogram was repeated four hours later and showed a QS pattern

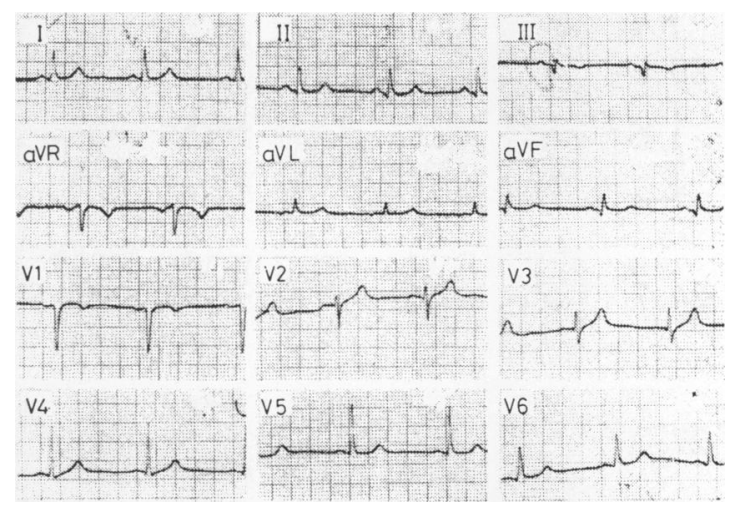

Fig. 1 Routine 12 lead electrocardiogram recorded about one year earlier. 
in V2 with a less prominent $\mathrm{T}$ wave in the praecordial leads (Fig. 2, second row). Within an hour, the pain subsided, the patient's clinical condition seemed good, the suspicion of an acute coronary event was dismissed, and he was discharged. The next morning the patient resumed his full physical activity and returned to his job as a construction worker. During the forthcoming weeks he complained of slight tiredness at work and, therefore, an electrocardiogram was performed on 24 July which showed a healing anteroseptal infarction (Fig. 2, third row). This finding led to the patient's admission to hospital. During his stay in hospital the patient showed no evidence of congestive heart failure and no arrhythmias were noted. Blood pressure was $120 / 80 \mathrm{mmHg}$ and the pulse was 84, regular. Physical examination showed no abnormalities, no signs of external trauma to the chest, and no local tenderness. Chest $x$-ray was normal and there were no fractures of the thoracic cage. Blood lipids and all serum enzymes were normal. Electrocardiogram showed an old anteroseptal infarction pattern (Fig. 2, fourth row).

Coronary arteriograms four months later showed complete occlusion of the left anterior descending artery with retrograde filling from the right coronary artery. All other coronary arteries were normal. Left ventriculography showed an akinetic anteroapical area.

\section{Discussion}

Blunt non-penetrating injury to the chest may rarely produce myocardial damage. ${ }^{1} \mathrm{~A}$ variety of cardiac manifestations can be evoked by nonpenetrating truma to the chest, of which the most serious are rupture of the myocardium, tear of valvular cusps or of chorda tendinae, and bleeding from pericardial or coronary vessels. ${ }^{2}$ Electrocardiographic abnormalities after a blunt injury to the chest are more frequent, and Watson and Bartholomae $^{3}$ reported a series of 42 patients with blunt chest injury, of whom $17(38 \%)$ showed electrocardiographic abnormalities consisting of flattening or inversion of $T$ waves and ST segment deviation. Acute myocardial infarction occurring after non-penetrating injury to the chest has also been reported, ${ }^{4-7}$ though only rarely with angiographic documentation of the occluded coronary arteries. ${ }^{8} 9$

In most of the sporadically described cases of an acute coronary artery occlusion associated with blunt chest trauma, pre-existing atherosclerotic coronary disease had been described, ${ }^{4} 10$ and it was assumed that in such cases the blunt chest trauma dislodged an already existing atheromatous plaque, thus obstructing the coronary artery. However, Jones ${ }^{7}$ and Oren et al. ${ }^{9}$ showed that coronary disease need not always be present in such cases and it was suggested that trauma may induce coronary artery occlusion and myocardial infarction as a result of injury to the coronary vessels rather than as a result of contusion of the heart muscle.

Blast injury to the heart caused by the transmission of positive pressure waves through an intact chest wall during detonation of a high explosive seems to be extremely rare, since

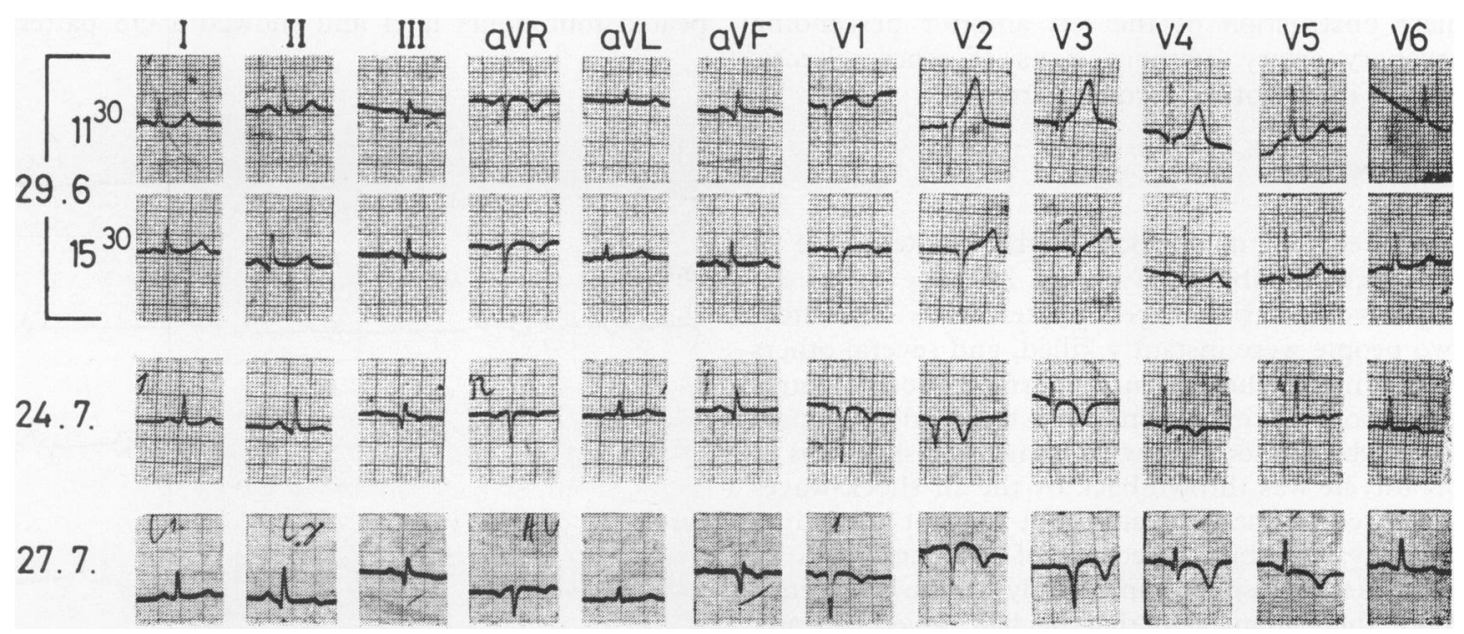

Fig. 2 Electrocardiographic tracings in the emergency room recorded on the day of the explosion (two upper rows), and about one month later (two lower rows). 
Naclerio $^{11}$ in his monograph devoted to chest injuries does not mention this type of lesion and reports only cases with pulmonary or abdominal damage. The only previous description of myocardial damage occurring after blast injury with ST segment depression and widening of the QRS complex was given by Basini and Hirsch, ${ }^{12}$ who described this occurrence in four victims of an underwater blast who also had extensive lung damage. Weiler-Ravell et al. ${ }^{13}$ described 13 patients who suffered underwater blast injury, of whom only three survived; the necropsy of one of the victims showed small areas of recent myocardial necrosis and subendocardial haemorrhages. It should be remembered that the amount of damage inflicted by the blast depends on the medium through which the pressure wave is transmitted, water being more dense than air and less compressible. Our case is, to the best of our knowledge, the first description of an acute myocardial infarction caused by exposure to an explosive blast transmitted by air waves without contact with any tangible object, though a pre-existing lesion at the site of the coronary occlusion cannot be entirely ruled out. It should be stressed, however, that the selective coronary angiography showed that all coronary arteries were free from any atheromatous plaques. We assume that the exposure to the blast-generated shock waves induced an intimal tear and/or subintimal haemorrhage with subsequent thrombosis which led to the myocardial infarction.

The authors thank Professor Shlomo Stern for initiating this study and for his help in the preparation of the manuscript.

\section{References}

1 Friedberg CK. Diseases of the heart, 3rd ed. Philadelphia: W B Saunders, 1966: 1697-706.
2 Parmley, LF, Manion WC, Mattingly TW. Nonpenetrating traumatic injury of the heart. Circulation 1958; 18: 371-96.

3 Watson JH, Bartholomae WM. Cardiac injury due to nonpenetrating chest trauma. Ann Intern Med 1960; 52: 871-80.

4 Borodkin HD, Massey FC. Myocardial trauma produced by nonpenetrating chest injury. Am Heart f 1957; 53: 795-801.

5 Lehmus HJ, Sundquist AB, Giddings LW. Coronary thrombosis with myocardial infarction secondary to nonpenetrating injury of the chest wall. Am Heart $\mathcal{f}$ $1964 ; 47: 470-3$.

6 Harthorne JW, Kantrowitz PA, Dinsmore RE, et al. Traumatic myocardial infarction, report of a case with normal coronary angiogram. Ann Intern Med 1957 ; 66: 341 .

7 Jones FL. Transmural myocardial necrosis after nonpenetrating cardiac trauma. Am f Cardiol 1970; 26: 419-22.

8 Stern $T$, Wolf R, Reichart B, Harrington OB, Crosby VG. Coronary artery occlusion resulting from blunt trauma. $\mathcal{F} A M A 1974 ; 230$ : 1308.

9 Oren A, Bar-Shlomo B, Stern S. Acute coronary occlusion following blunt injury to the chest in the absence of coronary atherosclerosis. Am Heart $\mathcal{f}$ 1976; 92: 501-5.

10 Levy HJ, Sundquist AB, Giddings LW. Traumatic coronary thrombosis with myocardial infarction. Arch Intern Med 1949; 84: 261-76.

11 Naclerio EA. Chest injuries. New York \& London: Grune and Stratton, 1971: 254-5.

12 Basini Y, Hirsch M. Blast injuries of the chest. Harefuah 1968; 75: 401-6.

13 Weiler-Ravell D, Adatto R, Borman JB. Blast injury to the chest. Isr f Med Sci 1975; 11: 268-74.

Requests for reprints to Dr Andre Keren, The Heiden Department of Cardiology, Bikur Cholim Hospital, POB 492, Jerusalem, Israel. 